\title{
JUEGOS ARAUCANOS DE LA PATAGONIA
}

\author{
POR RAUL MARTINEZ-CROVETTO
}

Durante el pasado verano tuvimos ocasión de realizar un prolongado viaje por la Patagonia, que abarcó las provincias de Río Negro, Neuquén y Chubut, habiendo sido su principal objetivo efectuar estudios sobre etnobotánica mapuche y gününa-kene. Como complemento de dicha labor, obtuvimos un interesante acopio de datos y observaciones relacionados con juegos y entretenimientos de estos aborígenes, parte de cuyo material ha servido para redactar el presente estudio.

Nos preocupamos principalmente de recoger información entre gente de edad, con el objeto de brindar al lector un panorama vinculado con la actividad lúdrica, lo más prístino posible, tal como ésta era realizada a fines del siglo pasado y principios del actual, épocas que aún perviven en la memoria de algunos y en las cuales, la trasculturación no era tan acentuada como ahora. En efecto, si antes eran "indios", ahora son "criollos" y a tal estado han evolucionado social y culturalmente. Significa esto, que nuestro material pertenece a un mundo en vías de desaparecer.

También prestamos atención a los juegos que los niños utilizan en el presente, procurando separar los que fueron adquiridos en la es. cuela o en el contacto con niños de diferente extracción, de aquellos que provienen de la tradición, lo eual no siempre resulta fácil ni seguro.

Los entretenimientos que describimos más abajo se pueden reunir en las siguientes categorías: juegos de azar (tres), de habilidad (ocho), deportivos (ocho), infantiles (cuatro) y juguetes (siete). 
No hemos incluído ciertos juegos de pelota, como "palín", "trumún" y "pilmatún", ya extintos, por cuanto existen varias descripciones de los mismos y los datos obtenidos por nosotros no agregan nada nuevo ni permiten mejorarlas.

En lo que se refiere a pasatiempos infantiles, hemos omitido los que oportunamente señalara la señora Koessler-Ilg (1962) para los araucanos del Neuquén, aunque algunos de ellos los hayamos observado en ésta o en alguna de las restantes provineias.

Como en contribuciones anteriores, tratamos aquí de establecer relaciones entre estos entretenimicntos y los de otras tribus aborígenes sudamericanas y de analizar y comparar la bibliografía a nuestro alcance, principalmente la vinculada con el área araucana. Ciertas consideraciones de esta naturaleza, que ya hiciéramos en nuestro estudio sobre juegos araucano-pampas (Martínez-Crovetto 1968 a) fueron omitidas en esta entrega, teniendo en cuenta lógicas razones de brevedad.

\section{JUEGOS DE AZAR}

1. Kechukán. - De este interesante juego, que, por lo menos dentro de los límites del país, debe darse por desaparecido, obtuvimos una excelente descripción de varios aborígenes en el centro de Chubut, la cual nos permitió reconstruirlo y realizar una partida a modo de ensayo. La variante que vamos a describir seguidamente era practicada también por gününa-kene o pampas y se realizaba entre dos.

Se dibuja, sobre el suelo, una suerte de tablero de forma circular, de unos $40 \mathrm{~cm}$ al que se le agregan dos diámetros perpendiculares entre sí en el interior. Se completa trazando cuatro rayitas en cada uno de los cuatro radios, de modo que equidisten, y seis en los respectivos sectores de circunferencia resultantes (Fig. 1). Constituyen éstas las "casillas".

Cuélgase de una viga del techo una soga con un lazo fijo en el extremo inferior, el cual deberá quedar suspendido a unos 30 ó $40 \mathrm{~cm}$ encima del "tablero".

Los demás elementos necesarios para el juego son los siguientes: un dado de piedra en forma de tetraedro, llamado "kechukáwe", que consta de cinco caras. Cuatro de ellas son triangulares y llevan, res. pectivamente, uno, dos, tres y cuatro puntos grabados; la base es rectangular y posee cinco puntos, de los cuales deriva el nombre del dado y del juego, pues "kechú" significa cinco. Para arrojarlo, se lo toma 
con el índice y pulgar derechos, se engancha el mayor en el lazo que pende del techo, e imprimiéndole un movimiento de balanceo, se suelta el "kechukáwe" de modo que caiga dentro del círculo. Si queda parado, es decir, apoyado sobre la eara rectangular o base, vale cinco o "kechú". Si lo hace sobre las caras triangulares, se toma en cuenta la cifra grabada en la cara que mira hacia arriba, pudiéndose obtener,

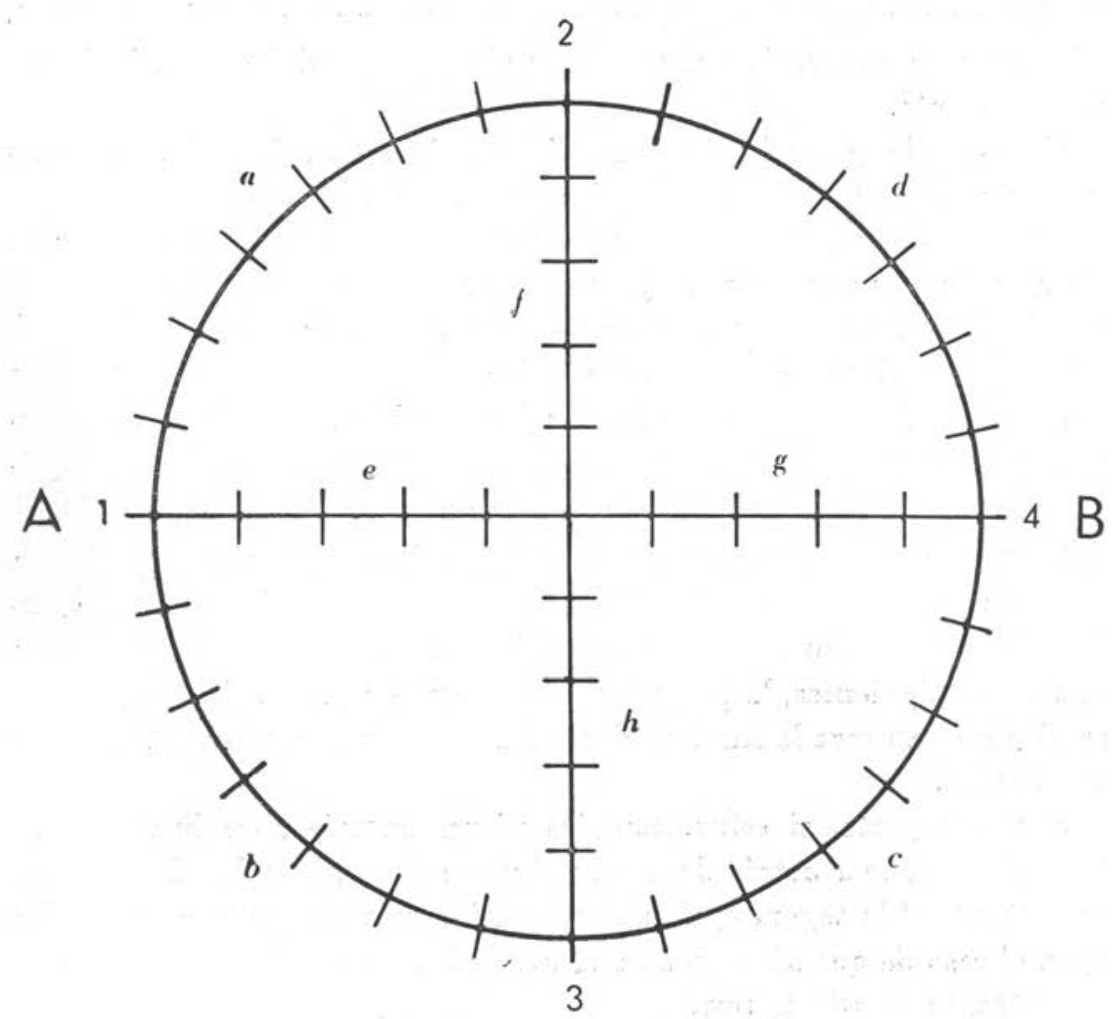

Fig. 1. - Tablero para el * kechukán *.

en consecuencia, "washú" (uno), "epú" (dos), "kelá" (tres) o "meli" (cuatro).

Tomando como referencia dicho puntaje; el jugador hace avanzar sobre el tablero uno de los diez "koná" (soldados) que posee y que consisten en palitos o trozos de ramitas de unos 4 ó $5 \mathrm{~cm}$ de largo. Estos, durante la partida, se colocan parados clavándolos en las casillas del tablero.

Para iniciar la lucha, el jugador $A$ (ver fig. 1) deja caer el dado de la manera indicada anteriormente y si obtiene, por ejemplo, "kelá", 
toma uno de sus palitos y usando como punto de iniciación el lugar indicado con 1 , lo hace avanzar por $a, b$ o $e$ según su criterio, tres casillas y lo clava. Tira a continuación el jugador $B$, repitiendo la maniobra descripta. Vuelve el dado a $A$, quien puede continuar moviendo su "koná" o bien, introducir otro en juego; esto último se considera una buena estrategia, pues en los momentos críticos, o sea cuando dos soldados enemigos se enfrentan, conviene tener varias fichas disponibles a fin de aprovechar el puntaje indicado por el dado en la forma más eficiente.

Como regla general, ninguna ficha puede retroceder. Si una perteneciente a $A$, que viene avanzando por $g$ llega a la casilla indicada con el número 4 en là fig. 1, debe continuar su marcha por $c$ o por $d$. En caso de que venga por $c$, debe elegir entre $d$ o g. Otro tanto sucede con las fichas de $B$ que lleguen o sobrepasen la casilla 1. Las que se detienen en el centro o en las casillas marcadas con 2 y 3 , pueden desviar su camino por $f, g$ y $h$, por $f$ o por $h$ respectivamente. Si durante la marcha, una ficha pasa por cualquiera de estos puntos, es obligación que continúe derecho sin desviarse.

Cuando, merced al puntaje obtenido, un "koná" cae en una casilla ocupada por un enemigo, lo "mata", eliminándolo del juego. En cambio, cuando el tiro lo lleva más allá de dicha casilla, quedando en una de las siguientes, la pieza contraria sigue en juego. En caso de que en el punto alcanzado hubiera dos o más soldados contrarios, todos son eliminados.

Por otra parte, si estuvieran dos piezas enemigas en lugares contiguos, o sea, una detrás de otra, no se puede pasar sobre la primera para "matar" la segunda, siendo necesario, entonces, mover otra ficha o, en el caso de que sólo quede una por haber sido "muertas" las nueve restantes, se pierde el tiro.

Un "koná", puede pasar por encima de un compañero y eliminar a un contrario que se halle ubicado en una de las casillas siguientes.

Quien consiga suprimir a todos los soldados enemigos, es el ganador.

Apostaban dinero o efectos personales y según Anastasio Tomás y Silverio Cual, aborígenes de extracción gününa-kene, residentes en Sierra Rosada, que vieron practicar asiduamente "kechukán" a sus respectivos progenitores, se trataba de una diversión exclusivamente masculina. Otro tanto nos aseguró el araucano Juan Yanquetruz, anciano que vive en Catatrao, paraje próximo a Sacanana.

En cuanto a los antecedentes históricos y bibliográficos relacionados con el tema, nos hemos ocupado brevemente en una publicación ante- 
rior (Etnobiológica $N^{\circ} 8: 2$ y 3), por lo eual aquí sólo nos referiremos a lo acotado por Guevara (1927: 361), en conexión con el carácter bélico del juego: "Fuera del interés pecuniario de este juego, tenía para los indios [araucanos de Chile] el de representar un combate o malón. Los palillos eran mocetones i la tierra del centro de la cruz i estremos de sus brazos, rucas de caciques". Afirmación que nos parece correcta.

Para los araucano-pehuenches del Neuquén, se conoce la descripción de una variante llamada "guaro, que es quechú o triángulo de madera, con varios puntos embutidos de alquimia o plomo", observada por el viajero Luis de la Cruz en 1806 (Cruz 1910: 307).

2. Awár kudéwe. - La existencia del juego de las habas, en el cual varios de estos elementos sirven a modo de dados de dos caras, es conocida desde el siglo xvir entre los araucanos de Chile. Más modernamente se lo ha reportado de la Patagonia argentina.

A través de la literatura consultada, aparece como un entretenimiento de azar realizado según numerosas variantes, en función de la época y del lugar. La primera versión que conocemos, corresponde a Ovalle $(1888,1: X L)$, cuya edición original es de 1646. Según este autor, utilizaban varios porotos "que son a manera de habas", con una de sus caras pintada de negro; se dejaban caer de la mano a través de un aro ubicado a cierta altura del suelo "y aquél se entiende ganar más puntos o rayas cuyos porotos cayeron con la parte pintada para arriba".

Según Olivares (1864: 42), cuyo manuscrito es anterior a 1788, "la suerte es el número par y el azar el número impar".

Carvallo y Goyeneche (1876: 158) escribió hacia 1796: "Son doce medias habas, la mitad negras i la otra mitad blancas; se tiran desde la abertura de la cabeza sobre una manta, i se pierde o se gana según el mayor número de negras que se descubren respecto de las blancas".

Otros autores, como Smith (1855:321), Manquilef (1914: 269), Ruíz Aldea (1902: 25), Augusta (1934: 32) y Housse (1940: 317) sostienen que se juega con ocho habas o con diez (Augusta 1934: 355).

El aborigen neuquino Paillalef (Alvarez 1962: 639) describió otra forma de jugar, utilizada en dicha provincia y en la cual se emplean seis habas.

A continuación vamos a reseñar dos variantes obtenidas, la primera en el lago Huechulafquén (Neuquén) y la otra en Lagunita Salada (Chubut). 
Primera variante. - Se utilizan diez habas pintadas de negro en una de sus caras y diez sin teñir. Antes de proceler a pintarlas, una de las caras es cuidadosamente labrada y luego, cnnegrecida con carbón.

El jugador arroja todas las habas, pudiendo obtener un tanto si el número de caras negras (y por ende de blancas) es par, ganar la partida si salen todas blancas y no anotar nada, si sale impar. Cada participante tira por turno una vez.

Las partidas se concertaban, por lo común, a 20 tantos, los cuales eran mareados con palitos. Las apuestas consistían principalmente en dinero.

En la zona de Huechulafquén, este juego se extinguió hace más de un cuarto de siglo.

Segunda variante. - Se emplean ocho habas pintadas por un lado. de negro como en el caso anterior. El puntaje es el siguiente:

$\begin{array}{ll}\text { Todas las caras blaneas: } & \text { gana el partido } \\ \text { Todas las caras negras: } & \text { gana el partido } \\ \text { Cuatro caras negras: } & \text { gana un tanto }\end{array}$

El participante que obtenía un tanto, continuaba tirando. Si arrojaba número impar de caras negras o cualquier otra combinación que no fuera ninguna de las indicadas arriba, le correspondía jugar a otro.

Por lo general se disputaban 10 tantos o bien otra cantidad preestablecida. Las apuestas consistían en dinero, ropa, reses, etc.

Según información del anciano Francisco Catrimai, de Lagunita Salada, esta variante se practicaba también en Junín de los Andes y era juego intrcducido por los norteños o "pikunche".

Un hecho interesante y que conviene destacar es que los elementos utilizados a modo de dados, las habas, son foráneos, pues dicha leguminosa (Vicia faba) es de antiquísimo cultivo en Europa y Oriente (Burkart 1952: 356) y desconocida en América antes de la conquista. Inclusive el vocablo awár (o awásh, como hemos oído también pronunciar en la Patagonia) no es más que un hispanismo ligeramente modificado y, muy posiblemente, incorporado al idioma araucano en épocas lejanas, cuando aún no sabían pronunciar la $b$, a la que raemplazaron por la $u$ consonante.

Ovalle, como hemos visto más arriba, dice que empleaban porotos, pero los demás historiadores del siglo xviII y posteriores que hemos consultado, siempre mencionan habas. 
Todos nuestros informantes araucanos, y pese a que insistimos mucho sobre dicho punto, estuvieron contestes en afirmar que se jugaba con éstas y no con porotos e, inclusive, varios de ellos fueron capaces de establecer las diferencias que existen entre ambas clases de semillas.

De cualquier manera, creemos que hay que aceptar el hecho de que primitivamenlte utilizaron porotos (véase lo dicho por Ovalle) y que luego adoptaron las habas por razones que desconocemos y que ninguno de los aborígenes consultados nos pudo explicar. Lo cual nos lleva a admitir que, si este tipo de juego es originario de las culturas peruanas, como es dable creer (véase a este respecto Nordenskiöld 1918 y 1929: 167 y Vivante 1946), se difundió hacia la Araucania antes de la conquista hispana.

3. Lliguén. - Este juego de azar con cuatro palitos cortados por el medio y utilizados como dados bifacéticos, es el mismo que, con el nombre de "mamuél kuzén" describimos para los araucanos de Los Toldos (Etnobiológica $\mathrm{n}^{0}$ 8: 5 y 6).

\section{JUEGOS DE HABILIDAD}

1. Tafá kuzén. - Se trata del conocido juego de la taba, que fue y sigue siendo aún muy importante, pese a las prohibiciones policiales. (Véase Etnobiológica $\mathrm{n}^{\circ}$ 8: 9.)

2. Pelalkantún. - Los juegos de hilos, de acuerdo con nuestras investigaciones de campo, adquirieron gran desarrollo entre los araucanos de la Patagonia, pese a lo cual han pasado desapercibidos hasta el presente. El abundante material recolectado por nosotros, no solamente entre los mencionados aborígenes, sino también entre gününakene, será objeto de una publicación especial y consiste en más de cuarenta figuras (algunas de ellas móviles), un juego de adivinación y varias pruebas de destreza.

3. Trapial kuzén. - 0 juego del león y los perros, del cual hemos anotado dos variantes que describiremos seguidamente:

Variante primera. - Obtenida en el lago Huechulafquén, según el araucano Valentín Cañicul.

Los elementos de juego consisten en 14 piedritas que reciben el nombre de "trewá" (perros)) y una piedra algo mayor que es "zomó trapiál" (leona) o simplemente "trapiál" (león). 
En el suelo se dibuja un tablero y en él se disponen las piedritas, que son a modo de fichas, en la forma indicada en la fig. 2a. La que representa el león se ubica en el tablero más pequeño, que recibe el nombre de "loló trapiál" (cueva del león).

Las piezas deben moverse, de a una por vez, siguiendo las líneas horizontales o verticales y ubicándose en las intersecciones de las mismas, que son equivalentes a las easillas del juego de damas. El movi-
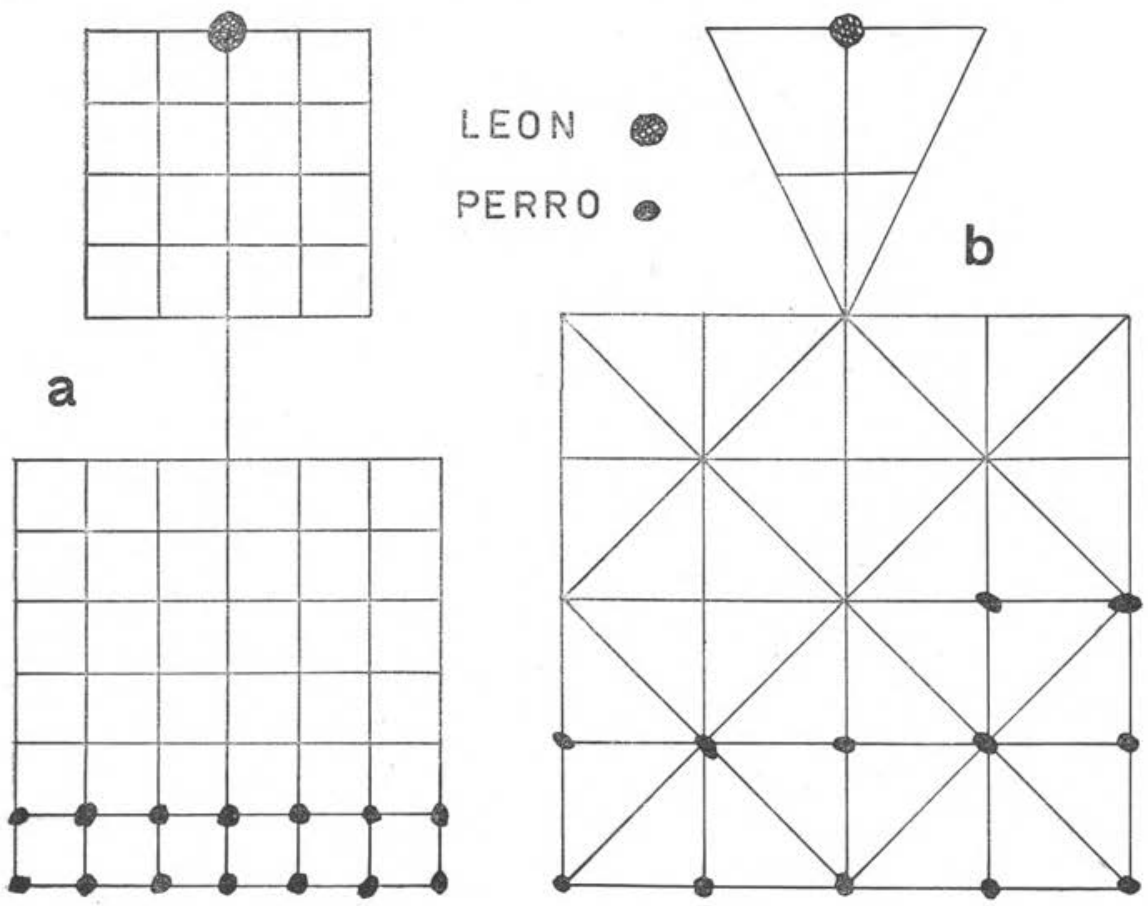

Fig. 2. - Tableros para el juego del lé́n.

miento es desde una casilla a la contigua. Los perros y el león pueden desplazarse hacia adelante, hacia atrás, o lateralmente.

Un jugador maneja los perros y otro el león. Se inicia la partida moviendo éste primero; luego corresponde mover un perro. El objetivo del juego es, para los perros, encerrar al león en su guarida o en cualquier lado del tablero e impedirle todo movimiento, pero son vencidos en caso de que el felino logre pasar su doble línea. Como en el juego de damas, el "trapiál" puede comer un "trewá", si éste no está apoyado por otro ubicado detrás, pero a diferencia de dicho entretenimiento, aquí se puede eliminar una pieza contraria hacia 
adelante, hacia atrás o lateralmente. Cuando el león devora un perro, pasa sobre éste y se ubica en la casilla situada detrás del mismo, según la dirección en que aquél viene.

Es necesario recalcar que el conductor de los perros, si no comete alguna equivocación, gana necesariamente la partida.

Variante segunda. - Anotada del gününa-kene Anastasio Tomás, pero también practicada antiguamente por araucanos en el centro de Chubut.

El tablero, dibujado en la fig. $2 \mathrm{~b}$, diverge del anterior por tener sólo cinco líneas horizontales y cinco verticales y, además, por estar cruzado por líneas oblicuas, siguiendo las cuales pueden moverse las piezas. La cueva del león difiere también en su forma y, como el tablero propiamente dicho, tiene menor número de casillas.

Se emplean aquí, por otra parte, doce perros en lugar de catorce.

Un juego muy parecido, practicado con un tablero para damas y denominado "perros y liebre", se juega muy comúnmente en el país, pero antecedentes históricos, que analizaremos a continuación, obligan a pensar que se trata de una diversión autóctona.

En primer lugar, tenemos la versión de Molina (1795: 124), quien lo observó hacia la segunda mitad del siglo xvIII: "Es digno de reflexión, que entre los primeros se encuentre allí en uso, desde tiempo inmemorial, el artificioso juego del agedrez, al que dan el nombre de comican".

También Gómez de Vidaurre (1889: 351) trae referencias al mismo: "Dan poco tiempo al juego del ajedrez que en ellos se halla desde tiempo inmemorial y que no puede dudarse que lo tenían aún antes de la entrada de los españoles pues le dan el nombre de comican".

A mediados del siglo xix, Smith (1855: 323) observó, también entre los araucanos ehilenos, un entretenimiento que le recordaba al ajedrez.

Modernamente, Manquilef (1914: 268-269) describe este juego, tal como lo practican algunos mapuches de Chile, quienes emplean un sistema similar, pero no igual, a los que hemos descripto más arriba. Concluye este autor sosteniendo que es muy parecido al que los niños chilenos llaman "leoncito" y que "komikán" quiere decir el cómeto todo.

En cuanto a este último vocablo, nuestras pesquisas resultaron infructuosas, pues ninguno de los varios aborígenes consultados lo conocía.

Entre los araucanos de Patagonia, el "trapiál kuzén" parece haber 
sido bastante usado por los adultes, principalmente los hombres, hasta las primeras décadas de este siglo, pero en la actualidad ha eaído en el desuso.

4. Saté. - Un curioso juego, del cual hemos aprendido dos variantes, pero que muy probablemente haya tenido otras, es el saté. Parece haber gozado de gran difusión a través de todo el norte de Patagonia, según las versiones recogidas entre diversos aborígenes ancianos, quienes recuerdan haber visto a sus padres entretenerse con él mientras descansaban al lado de los fogones. Sólo unos pocos de los consultados se acordaban de las reglas del mismo, lo cual, dada la edad de aquéllos, indicaría que su práctica cesó a fines del siglo pasado o eomienzos del presente.

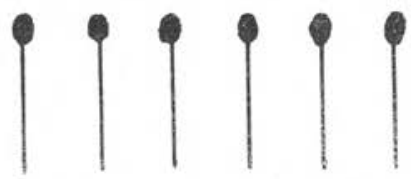

Fig. 3. - Tablero para el juego \& saté *.

- Variante primera. - Según información de Paula Navarrete, de N̄orquinco (Neuquén) el "saté" era jugado por hombres y mujeres y efectuaban toda clase de apuestas.

Se trazan seis rayitas paralelas en la ceniza y en la extremidad de cada uno colócase un trocito de carbón. Intervienen varios jugadores por turno. Al primero de ellos se le vendan los ojos, luego de haberse colocado de cuclillas de tal modo que las rayitas converjan hacia su persona y que los respectivos carboncitos queden ubicados en la extremidad distal de las mismas (fig. 3). Provisto de un trozo de caña colihue o "riñi", que toma con su mano derecha, trata de sacar con el mismo el pedacito de carbón ubicado en la primera línea de la derecha, no tocar el segundo, sacar el tercero, etc., hasta llegar a la sexta línea, mientras va diciendo "saté sí, saté no, saté si, saté no, saté sí, saté no". Como se está a ciegas y el movimiento debe efectuarse con cierta rapidez, resulta difícil hacer salir el carboncito de la línea a la cual corresponde "saté si" y por otra parte, no equivocarse y mover el que está en la línea siguiente cuando se exclama "saté no".

Completan así la ronda de jugadores y es ganador aquel que ha logrado pasar su prueba sin fallas ni errores. 
Variante segunda. - Obtenida del ya citado Valentín Cañicul del Lago Huechulafquén. Se juega entre dos. Trázanse varias rayas sobre el suelo, se le vendan los ojos a uno de los contrincantes el cual ha sido provisto de un trozo de caña colihue. El oponente dice "saté" y el vendado dice "sí", tratando de tocar con la caña la primera raya y así sucesivamente hasta la última, en que debe decir "no". A conse. cuencia de no poder ver en qué lugar se apoya el colihue, es muy probable que en el momento de detenerse el juego, lo haya ubicado lejos de la última raya, perdiendo entonces la apuesta y debiendo ceder el turno al otro.

Del "saté" no conocemos antecedentes.

5. Shipó. - Consiste en tomar el cuchillo por la punta y arrojarlo para que se clave contra un tronco, una tabla o el suelo.

Es un simple entretenimiento o se cruzan apuestas.

6. Añilwé. - Del juego de la payana, para el cual también anotamos el nombre "echíf kurrá" y que, además, era practicado por los gününa-kene, hemos recogido des variantes, una, la oportunamente descripta por nosotros para los guaraníes de Misiones (Etnobiológica $\mathrm{n}^{\circ}$ 6: 3-4) y que también señalamos para los araucanos de Los Toldos (Etnobiológica $\mathrm{n}^{\circ} 8: 13$ ) ; la otra es la siguiente:

Se practica entre dos y utilizan doce piedritas. En la primera fase del juego, el que inicia la partida las arroja al aire y en el dorso de la mano trata de recibir el mayor número posible, evitando que caigan al suelo. Envía éstas nuevamente al aire y las recoge con la palma; si falla, debe entregar las doce piedritas al contrario. Se inicia ahora la segunda fase. Supongamos que haya podido recoger cuatro; las aparta y tomando una de ellas, la arroja al aire y girando la mano trata de levantar del suelo el mayor número posible de las ocho res. tantes y recibir otra vez con la palma la que viene cayendo. Si no falla, o mueve alguna de éstas, aparta las que acaba de obtener, toma una de las tres que separó primero y repite la jugada, maniobrando de tal manera que, cuando utilice la última de las tres, pueda levantar todas las que restan en el suelo, sin que sobre ninguna. Por otro lado, debe cuidar que no quede ninguna de las piedritas que apartó al iniciar la partida. En caso de que lo logre, anota un punto a su favor y vuelve a jugar nuevamente desde el comienzo. En cambio, si se le terminan las piedritas que apartó y quedan todavía algunas en el suelo, el adversario toma éstas y juega con ellas de la manera descripta. Suponiendo que al rival le hayan sobrado cuatro, las toma 
entonces, las arroja al aire y las recoge en el dorso. Si retiene dos, por ejemplo, separa una, tira la otra para arriba y levanta una del suelo; pide dos piedritas al contrario y procede de la misma manera hasta que deje a éste sin las que había ganado previamente, con lo cual se anota un punto y comienza a jugar de nuevo con las doce.

En el caso de que uno de los adversarios falle o mueva una de las piedritas que están en el suelo, durante el desarrollo de la segunda fase del juego, debe entregar al otro las que separó al iniciarlo, pudiendo únicamente guardar las que recogió posteriormente.

Esta última variante, recogida en Choele-Choel, es utilizada actualmente por las niñas.

Los vocablos "añilwé" y "echíf kurrá" se oyen sólo en contadas ocasiones, siendo empleado comúnmente el término "payanca", corrupción de "payana", voz quichua de amplia difusión en el país. "Payanca" se utiliza también corrientemente en el sur de la provincia de Buenos Aires, pero entre gente no araucana.

7. Tekún. - El tejo araucano es practicado del siguiente modo:

Cada jugador se provee de dos piedras chatas y planas y, colocados éstos a algunos pasos de distancia de una raya previamente trazada sobre el suelo, las tiran por turno. El que consigue que una de sus piedras quede más cerca de dicha raya, gana un punto; si arrima las des, superando a sus contricantes, obtiene dos puntos.

Es vencedor aquel que logre, antes que los demás, una suma total de puntos igual a la que se estableció antes de comenzar.

Antecedentes de un juego así llamado por los araucanos de Chile, encontramos en Plath (1962: 178), aunque este autor no describe sus reglas. Por su parte Housse (1940: 366), siempre en relación con estos aborígenes, hace referencia a una suerte de tejo con el cual las mujeres se divierten durante la ceremonia de iniciación de la pubertad en las niñas.

Entretenimientos similares han sido señalados, entre otros, para aymaras (Bertonio 1612, 2: 321), chiriguanos (Nordenskiöld 1912: 171) y churapa (Nordenskiöld 1922: 27) ; hallazgos arqueológicos que podrían corresponder a piezas usadas como fichas para este juego, se han realizado en el área quichua (Rowe 1947: 288), comechingona (Serrano 1945: 119) y en el valle jujeño de San Francisco (Nordenskiöld 1920: 112).

Según Koessler-Ilg (1962: 182) "tekún" podría ser un hispanismo. 
8. Mamuél kudéwe, - En este juego de destreza, el que lo realiza toma un palito redondo, un trozo de rama por ejemplo, de unos 20 a $30 \mathrm{~cm}$ de largo por $1 \mathrm{~cm}$ de diámetro, entre los pulgares e índices de ambas manos, del modo indicado en la lámina Ia. Pasando el pulgar izquierdo por entre el pulgar y el índice derechos, se hacen girar las manos en sentido contrario, mientras se mantiene apretado el palito con la parte carnosa situada entre los mencionados dedos. De esta forma se llega a la posición indicada en la lámina Ib.

Primeramente acostumbran a hacer una demostración, la cual realizan con cierta presteza y luego desafían a alguno de los presentes a que repita la operación, o sea, a que invierta la posición de las manos sin soltar el palito, llegando inelusive a formalizar apuestas. La picardía del aborigen llega al extremo de efectuar la maniobra varias veces, para convencer al otro de que se trata de un malabarismo sercillo y, recién entonces, lo incita a apostar.

Como este juego es practicado en el país por gente de muy diferente extracción, pensamos que ha sido adoptado por los araucanos.

9. Konéu. - En la zona cordillerana del Neuquén, es de uso freeuente un tipo de adivinanza que creemos propio de los araucanos y que practican tanto adultos como niños.

El que inicia el juego pronuncia la primera sílaba del nombre de un ave y los presentes deben tratar de adivinar de cuál se trata.

La frase comúnmente utilizada es la siguiente:

"Shem piñéi aishém ka..."

Respuesta: "kanin" (jote).

La frase anterior significa: ¿Qué cosa se llama pájaro ka....?

Otra forma de adiv nanza, eonocida eomo "shishín kitrá", hallamo en el eentro de Chubut. En este easo se trata de que alguien diga el nombre de una persona, que puede estar presente o ausente, luego de que otro pronuncie la primera sílaba del mismo.

La fórmula utilizada para el juego dice:

"Múke kimpé nóie (o noyé) shishín kitrá néu Pe..."

El que sabe la respuesta responde:

"Piká llefún néu Pedro".

O bien:

"Féi piñé funém Pedro". 

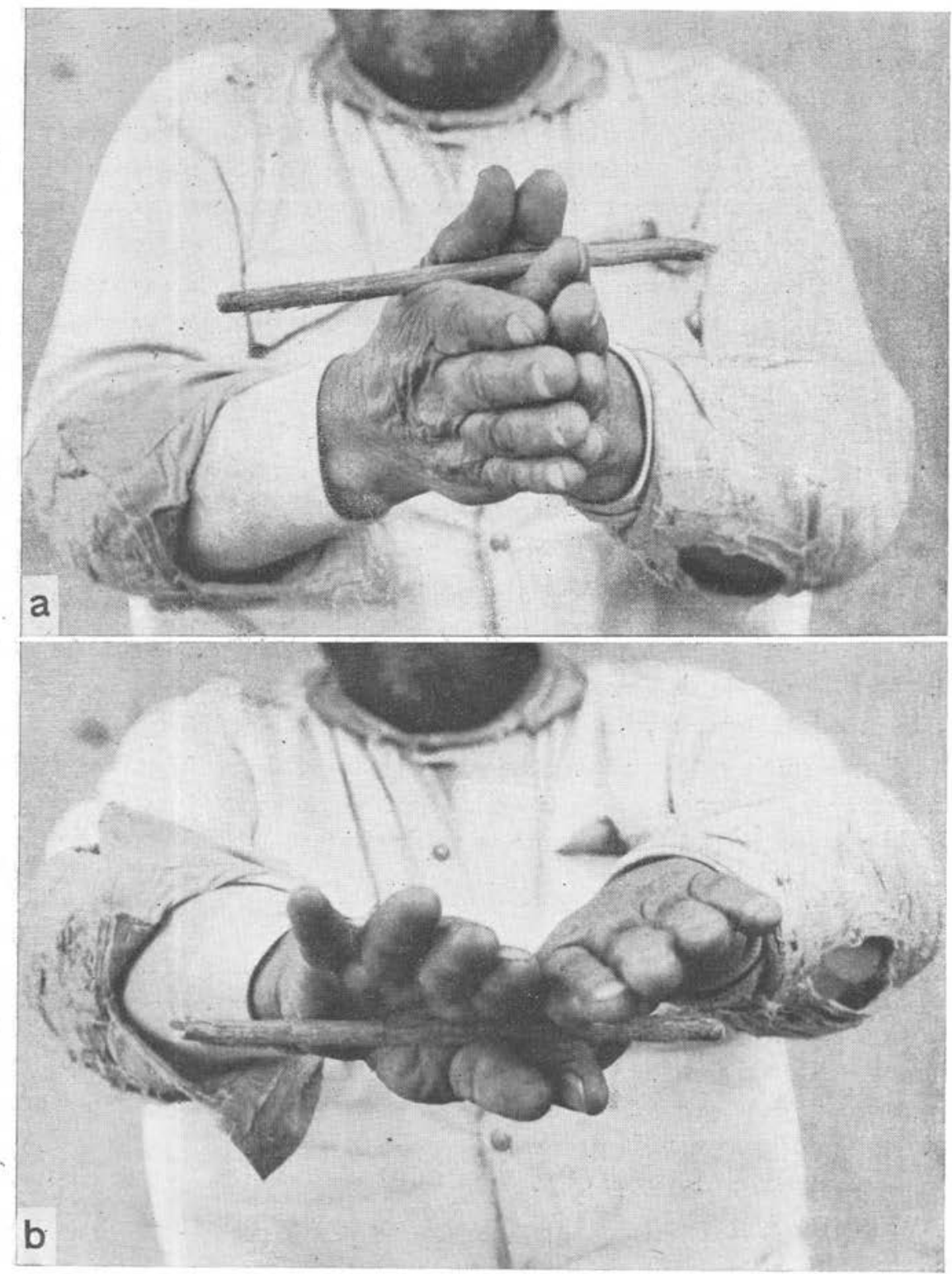

Lam. I. - «amuel kuzén $>$ : $a$, posición inicial : $b$, posición final, 
Pese a que insistimos ante nuestros informantes, no nos fue posible aclarar el significado exacto de las frases anteriores.

Los juegos de acertijos se conocen para caribes de Dominica, aymaras y araucanos (Cooper 1949: 511).

\section{JUEGOS DEPORTIVOS}

1. Lekái kudéwe. - Los ejercicios de destreza con boleadoras eran efectuados por hombres y mujeres. Para ello, los primeros utilizaban preferentemente la de tres ramales, mientras que éstas empleaban la de dos piedras. El juego más común consistía en arrojar el arma hacia un palo ubicado a unos $20 \mathrm{~m}$ de distancia procurando que se enrollara en el mismo. Los ganadores eran convenientemente premiados.

Lo mismo se practicaba ya en el siglo xviI entre los araucano-pampas (Paucke 1942, 1: 136). Según Sánchez Labrador (1936: 48) dichos aborígenes usaban como blanco para sus bolas un ala de avestruz clavada en el suelo y ganaba aquel cuyo implemento acertaba en ella o caía más cerca. En el siglo xix, D’Orbigny (1945; 3: 843) los vio emplear una lanza en vez de un palo con tal objeto.

2. Lasúi. - Era muy común, y aun continúa siéndolo, que durante ciertas labores ganaderas y también fuera de ellas, apostaran entre varios a quien enlazaba mejor alguna res. El que lograba un buen tiro con el lazo, llamado "lasú", era premiado con un trago de caña.

"Lasúi" quiere decir enlazar.

3. Aukantún cuchillo. - Se trata del varonil visteo con cuchillo que ya fue tratado en nuestro estudio sobre los juegos araucano-pampas (Etnobiológica $\mathrm{n}^{0}$ 8: 22).

5. Weluwitráo. - La cinchada de la soga se efectuaba entre hombres y para ello utilizaban un lazo o una soga de cuero sobado que pasaban por la parte posterior del cuello y por entre las piernas. Puestos ambos contricantes a gatas, cada uno tiraba para su lado (fig. 4). Previamente hacían una raya en el suelo, designaban un rayero y fijaban un límite de tiempo para la duración de la lucha en caso de empate.

Ganaba el que lograba arrastrar al contrario haciéndolo tocar la raya. "Weluwitráo" quiere decir tirante.

También solían realizar, con apuestas, cinchadas entre dos burros. 
6. Lefún. - Las carreras pedestres fueron muy utilizadas por jóvenes, niños y adultos, pues los araucanos consideraban que la velocidad era una cualidad varonil de mucha importancia.

Véase además Etnobiológica n 8: 21.

7. Kawél kuzén. - El deporte de los reyes fue uno de los que más atrajo, y todavía atrae, la atención de los araucanos. La forma de correr por parejas, sobre distancias de 200 ó $300 \mathrm{~m}$, era la usual. Al final de la pista o "ruín", se ubicaba el "komutún" o rayero. El jockey se llama "prakawél" o "perakawél".

Apostaban prendas de plata (cabestros, estribos, riendas, bozales), ropas, pulseras, pectorales y, en ocasiones, el caballo ensillado que montaban.

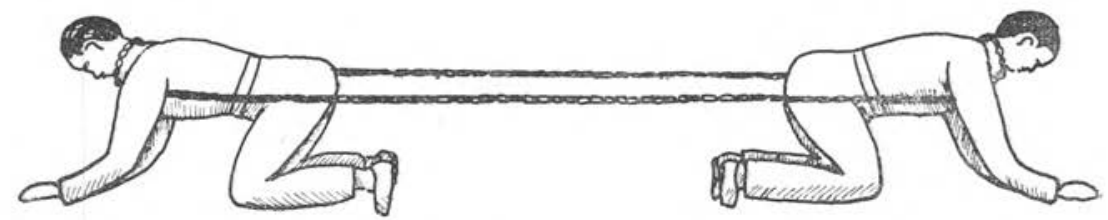

Fig. 4. - e Weluwitráo $>$ o einchada de la soga.

Hasta hace algunas décadas, había mujeres capaces de realizar exhorcismos para que un determinado flete ganara o perdiera. Uno de éstos consistía en colgarle una tortera de una pata para que se volviera más veloz.

8. Pratúi lofó. - De la doma de potros, que era una necesidad, hacían con mucha freeuencia, una diversión. Apostaban vino, caña, dinero, ropas, etc., a quien se mantenía más tiempo sobre un caballo arisco, en pelo y sin riendas.

"Pratúfe" se llama el domador o el que sube sobre un animal chúcaro.

Según Rusconi (1961: 406) durante la fiesta de "cata-cahuin", nuestros araucanos se entretenían de diversos modos, entre otros, domando potros. 


\section{JUEGOS INFANTILES}

Bajo este rubro vamos a considerar algunas diversiones exclusivas de los niños y de las cuales no conocemos antecedentes.

1. Kurrá. - Con piedritas y sobre el suelo hacían pequeños corrales. Otras piedras o huesos representaban animales. Así, trozos de espinazo eran vacas, huesitos de cordero, terneros. Con pedacitos de tallo de "chilca" (Baccharis sp.) simbolizaban a las personas. Un tallo con horqueta, clavado en forma invertida, era un hombre y tenía dos piernas. Un tallo recto era una mujer y tenía una sola pierna.

Durante el "día" los animales se sacaban del corral y se los distribuía por los alrededores. Mientras "pastoreaban", los cuidaban los palitos de "chilca" o sean, los hombres y las mujeres. Por la "noche" volvían a poner los animales en el corral.

Era juego de niños y niñas.

2. Traupitól kuzén. - Cuando florece el "traupitól" (Calceolaria varias especies) una diversión es muy común entre los niños, no sólo araucanos. Se coloca una flor, que tiene forma de zapatito, en la palma de una mano y con la otra se golpea, con lo cual el "traupitól" explota produciendo un fuerte ruido.

El mismo entretenimiento tienen en el centro de Chubut, pero ahora con las vainas infladas del "garbancillo" (Astragalus sp), cuyos frutos maduran desde mediados de enero y se mantienen tal cual durante bastante tiempo. Otra forma de entretenerse consiste en esparcirlos sobre el suelo y saltar encima varias veces provocando estampidos sucesivos.

3. Píchi ruká. - O casita. Los niños y niñas se divierten aún con este viejo juego, que heredaron de sus abuelos. Construyen pequeñas casitas con piedritas y barro, a las cuales ponen techo a una y dos aguas, construidos con palitos o ramitas. En el interior colocan muñecas hechas de trapo o con una rama en forma de horqueta. Las casitas están amuebladas con camas de pasto y otros elementos que representan muebles.

4. Aukantún.-- La lucha, sin reglas y sin jueces, es uno de los pasatiempos favoritos de los chicos.

5. Pilchílwe. - El columpio, hecho con una soga cuyos extremos penden de una rama, es una diversión infantil generalizada en la región 
de la Cordillera. En la Meseta patagónica, donde no hay árboles adecuados para ello, no lo hemos observado.

\section{JUGUETES}

1. Chizomó (o chidómo).--- Las muñecas, juguetes infaltables entre casi todas las niñas del mundo, eran hechas con palitos en forma de horqueta y, más generalmente, con trapos atados con lana para imitar el pelo. Las pequeñas araucanas se entretenían, como hoy en día, en hacerles vestidos utilizando telas viejas.

2. Trentrikáwe. - En la zona cordillerana, los zancos se fabrican con dos pedazos de caña colihue, los cuales, a unos 0,40 ó $0,50 \mathrm{~m}$ de un extremo llevan atados sendos trocitos de caña perpendicularmente; servirán éstos para apoyar el pie.

En otras regiones utilizan ramas con una horqueta dispuesta adecuadamente; a la que se sujeta un tarugo atravesado.

El posapié queda del lado interno; el extremo superior se toma con la mano y ambos zancos quedan ubicados delante del pecho.

Se trata de un juguete bastante empleado por los niños, quienes son muy hábiles en su manejo, pues son capaces hasta de correr con elles. Los adultos también suelen usarlos, especialmente para cruzar arroyos o ríos.

Los mapuches de Chile los conocen desde antiguo (Manquilef 1914: 275; Cooper 1947: 740) y también se los ha citado para los araucanos de Neuquén (Koessler-Ilg 1962: 184). Según Cooper (loc. cit.) serían nativos y no introducidos por los españoles.

3. Tren. - Para la fabricación de trompos usaron diversos materiales, según los lugares y épocas.

En la región de las araucarias, se los confeccionaba con un piñón de "pewén" (Araucaria araucana) agujereado longitudinalmente y atravesado por un palito o una astilla de colihue aguzado en un extremo. Se los hacía girar, impulsándolos con los dedos, sobre un cuero o sobre la palma de la mano y los empleaban hombres y niños como simple diversión. A veces eran lanzados de a dos, procurando que chocaran entre sí, de tal modo que un trompo volteara al otro.

Pero, el modelo de mayor difusión y que aún se usa, está hecho con un carretel de hilo de coser, por cuyo agujero central pasa un palito de punta aguzada. 
También fabrican o emplean trompos piriformes con punta de ace. re, de tipo europeo, los cuales son puestos en rotación mediante un hilo enrollado.

El vocablo "tren" recogido por nosotros, es el comúnmente usado. para este adminículo por los aborígenes del norte de Patagonia. "Pirói", término que figura en el diccionario de Erize (1960: 331), no fue reconocido por ninguno de nuestros informantes.

4. Lekái. - Las boleadoras de juguete difieren en el material empleado para su elaboración, según la edad del niño. Los muy pequeños las hacen de trapos envueltos en tiras de medias viejas; cuando más grandecitos, atan huesitos, palitos, piedritas o trocitos de hierro cnvueltos con un trapo, a la extremidad de un hilo.

Con estos implementos bolean gallinas, perdices, pájaros, perros, ete.

5. Witrukuráwe. - La honda, tejida con hilos de lana de manu. factura propia, era muy utilizada por los niños para cazar pájaros. Actualmente la va reemplazando la honda tipo "gomera".

6. Furfúrwe.-El palo zumbador, juguete bastante difundido entre los niños araucanos, se construye con una tablita agujereada en un extremo, por cuyo agujero pasa un hilo. En la zona cordillerana, se emplea un trozo de colihue al cual, mediante dos cortes longitudinales paralelos, se le eliminan dos lados, dejándolo plano. El orificio destinado al hilo, es practicado con un alambre caliente.

Antiguamente, en la región de Lagunita Salada, los niños revoleaban sus palos zumbadores durante las tormentas para hacer llover.

El vocablo "furfúrwe" fue recogido en Chubut. En el límite con Chile se lo denomina "run-run".

Con el hallazgo de este juguete en la Patagonia, que muy probablemente desciende del "run-run", consistente en una varilla de canelo atada al extremo de un hilo y que las "machis" hacían girar para ahuyentar al demonio (Alvarez 1968: 122), se amplía considerablemente su área de dispersión en América del Sur, tema del cual nos hemos ocupado en Etnobiológica $\mathrm{n}^{\circ}$ 6: 18.

7. Pifillkáwe.-El disco zumbador, otro juguete aborigen cuya área es necesario extender hasta la Patagonia, se fabrica con una rodaja de cuero o de palo con dos perforaciones cerca del centro y el borde dentado. De su manejo y difusión nos hemes ocupado en nuestro estudio sobre los juegos de los indios guaraníes (Martínez-Crovetto. 1968: 18-19). 


\section{VOCABULARIO RELATIVO A JUEGOS}

En la breve colección de vocablos que insertamos a continuación, hemos incluído la terminología empleada por los araucanos que habitan en el norte de la Patagonia, en relación con el tema que nos ocupa. Gran parte de dichos aborígenes, según creemos, provienen originalmente de la región pampeana y hablan el dialecto que denominamos "araucano-pampa". Se caracteriza éste porque la mayoría de las palabras son agudas y, además, por el uso de $z$ en vez de $d$, de $f$ en vez de $v$, etc.

En la región cordillerana, principalmente hacia los límites con Chile, predomina, aunque en forma no absoluta, el modo de hablar de los araucanos chilenos, en cuyo dialecto, es común la expresión llana, con excepción de los vocablos terminados en consonante, los cuales, las más de las veces, son agudos. Por otra parte, parece no existir la $z$, usándose en cambio la $d$, mientras que el empleo de $v$ of suele ser indistinto. De este modo, un araucano pampa dirá "zomó" por mujer, mientras que uno de Chile pronunciará "dómo". El idioma araucano, "chezugú" para los de la meseta patagónica, es "chedúgu" para los cordilleranos.

Otra consonante que aparece en el habla de nuestros araucanos es $s h$, a veces en reemplazo de $c h$ y otras de $s$. A éstas hay que agregar la $r r$, para el caso fuertemente fricativa, que el mapuche chileno no usa. Así unos dirán "kurrá" por piedra y los otros, "kúra".

De cualquier forma, hemos respetado lo más fielmente posible dichas modalidades dialectales, tal como las oímos de nuestros informantes y, cuando, distintos individuos han pronunciado de manera diferente, incluímos entre paréntesis la forma menos utilizada.

Advertencia. - El alfabeto usado para transcribir los vocablos araucanos, concide con la pronunciación castellana, salvo en los casos siguientes:

e como en francés petit.

$u$ como en francés lune.

$\mathrm{k}$ como ca, que, qui, co, cu.

$n$ es una n seguida de una oclusión gutural, sonando casi como $\mathrm{n}(\mathrm{g})$. Entre los araucanos de Patagonia se observa la tendencia a reemplazar esta consonante por la $\tilde{\text { n. }}$ 
rr (y $\mathrm{r}$ al eomienzo de las palabras), es una ápico-alveolar vibrante fuertemente fricativa.

tr la t suena como en español y la $\mathrm{r}$ es la ápico-alveolar débil fuertemente fricativa.

w es la u consonante.

$\mathrm{z}$ como th inglesa en thing.

añilwé, juego de la payana.

aukantún, lucha infantil.

aukantún cuchillo, prueba de visteo con cuchillo.

awar (o áwásh), haba (Vicia faba).

awár (o awásh) kudéwe, juego de azar con habas.

chizomó (o chidómo), muñeca; tal vez apócope de pichi zomó, mujercita.

echíf kurrá, juego de la payana; lit.: tirar piedra hacia arriba.

epú, dos puntos en el juego del kechukán; lit.: dos.

furfúrwe, palo zumbador.

kawél (o kawéll) kuzén, carrera de caballos.

wechú, cinco puntos en el juego del kechukán; lit.: cinco.

kechukán, juego de azar con dado pentafacético.

kechukáwe, dado para jugar el kechukán.

kéla, tres puntos en el juego del kechukán; lit.: tres.

komikán, nombre aplicado por los araucanos de Chile al trapiál kuzén. komutún, juez de raya para las carreras de caballos.

koná, ficha de juego empleada en el kechukán; lit.: soldado.

konéu, adivinanza.

kurrá, juego infantil con piedritas.

lasú, lazo.

Iasúi, enlazar.

lefún, carrera pedestre.

lekái, boleadora.

lekái kudéwe, juego consistente en bolear un palo.

loló trapiál, porción del tablero utilizado en el trapiál kusén; lit.: cueva del león.

lliguén, juego de azar con cuatro palitos utilizados como dados bifaticos.

mamuél kudéwe, juego de habilidad practicado con un palito. mamuél kuzén, sinónimo de lliguén.

melí, cuatro puntos en el juego del kechukán; lit.: cuatro.

pelalkantún, juego de hilo. 
perakawél (o prakawél), jockey; lit.: el que monta a caballo. pewén, Araucaria araucana.

píchi ruká, juego de las casitas; lit.: casita.

pifilkáwe, disco zumbador.

pilchílwe, columpio de soga.

pratúfe, domador.

pratúi lofó, doma de potros.

riñí (o riní), caña colihue (Chusquea culeou).

ruín, pista destinada a la carrera de caballos.

run-run, palo zumbador.

saté, juego de habilidad propio de los araucanos de la Patagonia.

shipó, juego consistente en clavar un euchillo.

shishín kitrá, adivinanza.

tafá kuzén, juego de la taba.

tekún, juego del tejo; tal vez un hispanismo.

topeltún, lucha tomándose del cuello.

trapiál, ficha utilizada en el trapiál kuzén; lit.: león.

trapiál kuzén, juego del león y los perros.

traupitól, Calceolaria varias especies.

traupitól kuzén, juego infantil con flores de Calceolaria.

tren, trompo.

trentrikáwe, zancos.

trewá, ficha utilizada en el trapiál kuzén; lit.: perro.

washú, un punto en el juego del kechukán; lit.: huérfano.

weluwitráo, cinchada de la soga; lit.: tirante.

witrukuráwe, honda aborigen.

zomó trapiál, ficha empleada en el trapiál kuzén; lit.: leona.

\section{RESUMEN}

Se estudian los juegos practicados por los indios araucanos de la Patagonia, a fines del siglo pasado y comienzos del presente según información de aborígenes que habitan en las provincias de Río Negro, Neuquén y Chubut. Se describen tres juegos de azar, ocho de habilidad, ocho deportivos, cuatro infantiles y siete juguetes. Completa el trabajo un vocabulario relativo al tema. 


\section{BIBLIOGRAFIA CITADA}

Alvarez, G. 1962. Algunas costumbres interesantes del aborigen del Neuquén. Bol. Acad. Nac. Historia 33: 623-64l.

- 1968. El tronco de Oro. Folklore del Neuquén. Buenos Aires.

Augusta, F. J. be, 1934. Lecturas araucanas. $2^{\text {a }}$ ed. Padre Las Casas.

Bertonio, L. 1612. Vocabulario de la lengua aymara. 2 vol. Iuli Pueblo.

Burkart, A. 1952. Las Leguminosas argentinas silvestres y cultivadas. $2^{\text {a }}$ ed. Buenos Aires.

Carvallo y Goyeneche, V. 1876. Segunda parte de la descripción histórico-jeográfica del reino de Chile. En Col. Hist. Chile vol. 10, Santiago de Chile. (Manuscrito original escrito c. 1796).

Cooper, J. M. 1947. The Araucanians. Handb. South Amer. Indians 2: 687-760. 1949. Games and Gambling. Handb. South Amer. Indians 5: 503-524.

Cruz, L. de la, 1910. Tratado importante para el perfecto conocimiento de los indios Peguenches, según el orden de su vida. En P. de Angelis, Col. Obras Doc. Hist. Río de la Plata 1: 283-307. $2^{\text {a }}$ ed. Buenos Aires.

D’Orbigny, A. 1945. Viaje a la América Meridional realizado en 1826 a 1833.4 vol. Buenos Aires.

ErIzE, E. 1960. Diccionario comentado mapuche-español. Cuadernos del Sur, Inst. de Humanidades Univ. Nac. del Sur. Buenos Aires.

Gómez de Vidaurre, F. 1889. Historia geográfica, natural y civil del reino de Chile. En Col. Hist. Chile vol. 14. Santiago de Chile.

Guevara, T. 1927. Historia de Chile. Chile prehispano. Vol. 2. Santiago de Chile.

Housse, R. E. 1940. Epopeya india. Trad. A. Gay. Santiago de Chile.

Koessler-Ilg, B. 1962. Tradiciones araucanas. Instituto de Filología, Fac. Humanidades y Ciencias de la Educación, Univ. Nac. La Plata. Vol. 1.

Manquilef, M. 1914. Comentarios del pueblo araucano. II. La jimnasia nacional (juegos, ejercicio i bailes). An. Univ. Chile 134: 257-301 y 801-883.

Martínez-Crovetto, R. 1968. Juegos y deportes de los indios guaraníes de Misiones. Etnobiológica $\mathbf{n}^{\circ} 6$.

- 1968 a. Estudios sobre juegos araucano-pampas. Etnobiológica $n^{\circ} 8$.

Molina, J. I. 1795. Compendio de la historia civil del reyno de Chile. Parte segunda. Trad. de N. de la Cruz y Bahamonde, Madrid.

NondenskiöLD, E. 1918. Spieltische aus Peru und Ecuador. Zeitschrift für Ethnologie 50 : 166-171.

- 1920. The changes in the material culture of two indians tribes under the influence of new surroundings. Comp. Ethn. Studies 2. Götteborg.

- 1922. Indianer und Weisse in Nordostbolivien. Stuttgart.

- 1929. Analyse ethno-géographique de la culture matérielle de deux tribus Indiennes du Gran Chaco. Trad. M. de Luppé. París.

Olivares, M. DE, 1864. Historia militar, civil y sagrada de lo acaecido en İa conquista y pacificación del reino de Chile. Col. Hist. Chile. Vol. 4. Santiago (Obra escrita antes de 1788).

Ovalle, A. De, 1888. Histórica relación del reino de Chile. Col. Hist. Chile vol. 12. Santiago de Chile (Edición original de 1646). 
Paucke F, 1942-44. Hacia acá y para allá (una estada entre los indios mocobíes, 1749-1767). Trad. E. Wernicke. Vol. 1 (1942). Tucumán-Buenos Aires.

Plath, O. 1962. Folklore chileno. $2^{\mathrm{a}}$ ed. Santiago.

Rowe, J. H. 1947. Inca culture at the time of the Spanish conquest. Handb. South Amer. Indians 2: 183-330.

Ruíz AldeA, P. 1902. Los araucanos i sus costumbres. Santiago.

Rusconi, C. 1961. Poblaciones pre y posthispánicas de Mendoza. Vol. 1, Etnografía. Mendoza.

Sánchez Labrador, J. 1936. Paraguay Catholico. Los indios pampas, puelches, patagones. Buenos Aires.

Serrano, A. 1945. Los Comechingones. Córdoba.

Smirh, E. R. 1855. The Araucanians; or, notes of a tour among the indian tribes of southern Chili. New York.

Vivante, A. 1946. Un antiguo juego peruano. Rev. Geogr. Amer. 26 (154) : 27-33. 